\title{
Gambaran coping strategies pada mahasiswa Universitas Padjadjaran
}

\author{
Ananda Nadhifasya Nursadrina ${ }^{* 1}$, Dhini Andriani ${ }^{2}$ \\ ${ }^{1,2}$ Fakultas Psikologi Universitas Padjadjaran \\ Jl. Raya Bandung Sumedang KM. 21 Kabupaten Sumedang, Jawa Barat 45363 \\ e-mail: ${ }^{* 1}$ ananda16003@mail.unpad.ac.id, 20hini.andriani@unpad.ac.id
}

\begin{abstract}
Stress is a part of college students' lives. If students do not cope well with stress, there would be higher risks of problems, ranging from academic performance to a health problem. How individuals cope with stress is called coping strategies. This research aimed to find out what kind of coping strategies used by students of Universitas Padjadjaran. Data consist of 339 students selected through convenient sampling was collected through online forms. Coping strategies were measured using the COPE Inventory. The most used coping strategy among students is turning to religion, which was followed by positive reinterpretation and growth. Maladaptive coping strategies, such as focusing on and venting of emotion and mental disengagement were still commonly used. This called for a solution to reduce the use of such strategies. Next studies can further investigate the effectiveness of coping strategies, by looking at stress level experienced and its link to both dispositional and situational coping strategies.
\end{abstract}

Keywords: stress; coping strategies; college students

\begin{abstract}
Abstrak. Stres berkaitan dengan kehidupan mahasiswa. Ketika tidak diatasi dengan tepat, risiko berbagai permasalahan dapat terjadi, mulai dari performa akademik hingga kesehatan. Oleh karena itu, coping strategies menjadi penting. Riset ini bertujuan untuk mencari tahu jenis coping strategies yang digunakan oleh mahasiswa. Pengumpulan data dilakukan secara online dan menggunakan convenient sampling diperoleh 339 responden mahasiswa Universitas Padjadjaran. Coping strategies diukur menggunakan COPE Inventory yang telah diadaptasi ke dalam bahasa Indonesia. Hasil penelitian ini menunjukkan bahwa coping strategy yang paling sering digunakan oleh mahasiswa Universitas Padjadjaran adalah turning to religion yang kemudian diikuti oleh positive reinterpretation and growth. Maladaptive coping strategies seperti focusing on and venting of emotion serta mental disengagement masih kerap digunakan sehingga diperlukan solusi untuk mengurangi strategi-strategi tersebut. Penelitian selanjutnya dapat mengeksplorasi lebih lanjut mengenai keefektivan coping strategies dengan mempertimbangkan tingkat stres yang dialami individu, dan melihat hubungannya dengan disposisional dan situasional coping strategies.
\end{abstract}

Kata kunci: stres; coping strategies; mahasiswa 


\section{Pendahuluan}

Stres merupakan hubungan antara individu dengan lingkungannya yang dimaknai oleh individu sebagai hal yang menekan (Lazarus \& Folkman, 1984). Situasi yang dapat menimbulkan stres disebut sebagai stresor (Lazarus, Richard S; Folkman, 1984; Lazarus, 1993). Kehidupan mahasiswa dapat dipenuhi oleh berbagai stresor. Sumber stres ini dapat dikategorikan ke dalam lima faktor yakni, akademis, keuangan, keluarga, sosial, dan kehidupan sehari-hari (Brougham et, al., 2009). Faktor yang paling erat dengan peran sebagai mahasiswa adalah faktor akademis, yang meliputi tekanan dan tuntutan untuk mencapai keberhasilan serta ketidakpastian masa depan (Shaikh, 2004). Stres pada mahasiswa juga dapat berasal dari rasa takut akan kegagalan, tugas yang terlalu banyak, serta time management yang buruk (Percall dan Keim, 2007).

Ketika membicarakan tentang stres, yang dimaksud oleh kebanyakan orang adalah distress atau stres yang negatif ( $\mathrm{Li}, \mathrm{CaO}, \& \mathrm{Li}, 2016)$. Distress merupakan stres yang menimbulkan perasaan dan reaksi tubuh yang negatif, sementara stres yang diiringi dengan perasaan dan reaksi tubuh yang positif dinamakan eustress (Lazarus, 1993). Akan tetapi, pada kenyataannya, stres merupakan sebuah proses yang kompleks dan tidak hanya mengandung sekedar elemen negatif atau positif saja (Folkman \& Lazarus, 1985). Proses ini dapat dinyatakan dalam bentuk hubungan antara individu dan lingkungannya, Berbagai bentuk hubungan antara individu dengan lingkungannya dapat menimbulkan pemaknaan yang berbeda-beda bagi individu. Individu dapat memaknakan stres sebagai hal yang merugikan, mengancam, menantang, atau bermanfaat. Berdasarkan pemaknaan tersebut, stres dapat digolongkan ke dalam tiga jenis, yakni challenge, harm, dan threat (Lazarus, 1993). Challenge merupakan stres yang kesulitannya masih dirasa dapat ditangani dengan baik, sedangkan harm merupakan jenis stres dimana kerugian yang diakibatkannya telah terjadi. Jika belum terjadi dan baru diantisipasi, maka stres tersebut tergolong ke dalam jenis threat.

Threat akan menimbulkan distress, dan hal ini dapat berujung pada berbagai permasalahan. Stres dapat menghambat proses belajar dan fungsi kognitif (Schwabe, Joëls, Roozendaal, Wolf, \& Oitzl, 2012). Hal ini berkaitan dengan memori dan waktu terjadinya stres. Stres yang dialami saat atau sesaat sebelum proses encoding informasi akan membantu proses konsolidasi memori. Akan tetapi, stres yang dialami jauh sebelum proses encoding akan menghambat pembentukan memori. Stres pun dapat menghambat proses retrieval memori dan pembaharuan memori atas apa yang dipelajari. Stres tidak hanya berdampak pada long-term memory, tetapi juga working memory. Ketika stres, pre-frontal cortex mengalami ketidakseimbangan neurochemical yang menyebakan terganggunya working memory (Shansky dan Lipps, 2013). Stres juga merupakan salah satu faktor yang berperan dalam progress berbagai penyakit seperti, depresi, kardiovaskular, HIV/AIDS, dan kanker (Cohen, Janicki-Deverts, \& Miller, 2007). Selain itu, stres juga dapat memprediksi berbagai hal pada mahasiswa seperti, menurunnya kesehatan fisik (Pritchard, Wilson, \& Yamnitz, 2007), menurunnya performa akademik (Melaku, Mossie, \& Negash, 2015; Sajid, Ahmad, \& Khalid, 2015), meningkatnya perilaku yang berdampak buruk bagi kesehatan seperti mengonsumsi alkohol (Melaku et al., 2015; Pritchard et al., 2007) serta merokok dan menggunakan obat-obatan terlarang (Melaku, et, al., 2015).

Ketika distress terjadi, individu akan berusaha untuk mengubah ataupun memaknai kembali hubungannya dengan lingkungannya tersebut menjadi hal yang dapat lebih diterima olehnya. Usaha ini disebut sebagai coping (Lazarus, 1993). Coping merupakan proses dimana individu mengelola stresor yang ia nilai telah melebihi kapasitas dirinya untuk menghadapi tuntutan internal dan lingkungan (Lazarus \& Launier, 1978; Ogden, 2004; Ryan, 2013). 
Pada awalnya, Lazarus \& Folkman (1984) mengajukan dua kategori coping strategies yaitu problem focused coping dan emotion focused coping. Kedua coping strategies tersebut dapat digunakan oleh setiap orang bergantung pada situasi yang dihadapi dan apa yang dapat dilakukannya pada saat itu (Folkman, et.,al., 1986).

Menurut Carver, Scheier, dan Weintraub (1989), problem-focused coping terdiri dari active coping, atau secara aktif mengatasi stresor dan mengurangi dampak yang ditimbulkan oleh stresor; planning, atau memikirkan cara untuk untuk menghadapi stresor; suppression of competing activity, atau mengesampingkan hal-hal lain yang tidak berhubungan dengan usaha untuk mengatasi stresor, dan menjaga agar jangan sampai terdistraksi dari hal-hal tersebut; restraint coping, atau menunggu hingga datang kesempatan untuk bertindak mengatasi stresor dan menjaga diri agar tidak bertindak dengan tergesa-gesa; dan seeking social support for instrumental reason atau mencari saran, informasi, atau bantuan dari orang lain untuk mengatasi stresor.

Ketika seseorang mencari dukungan sosial demi simpati, pengertian, dan dukungan moral dari orang lain, hal ini disebut dengan seeking social support for emotional reason yang tergolong ke dalam emotion-focused coping yang adaptif jika tidak berujung pada pencurahan emosi yang maladaptif. Emotion-focused coping juga mencakup positive reinterpretation and growth atau positive reapraisal, yang merupakan usaha untuk mengelola distres emotions yang dirasakan alih-alih menangani hal yang menyebabkan munculnya stres itu sendiri, memaknai stres yang dialami sebagai hal yang positif kemudian akan membantu individu untuk melakukan active problem-focused coping; denial, atau menyangkal keberadaan stresor ataupun bertindak seolah-olah stresor tersebut tidak ada, yang mana berguna jika stresor tersebut memang sesuatu yang dapat diabaikan; acceptance, atau menerima kenyataan dari situasi yang menyebabkan stres, yang mana berguna jika stresor bukan merupakan hal yang mudah diubah dan mengharuskan individu untuk terbiasa terhadapnya, turning to religion atau beralih kepada agama saat stres, yang mana dapat dilakukan dengan berbagai alasan, yang berkaitan dengan strategi lainnya, yaitu seeking for emotional support, positive reinterpretation and growth, serta active coping.

Penggunaan suatu jenis coping strategies dapat menjadi tidak tepat dalam situasi tertentu. Hal ini menimbulkan pertanyaan mengenai adanya coping strategies yang maladaptif. Dalam mengembangkan dimensi-dimensi coping strategies, Carver et al., (1989) pun menemukan beberapa bentuk maladaptive coping, seperti berfokus pada emosi yang dirasakan saat mengalami distress dan mencurahkan emosi tersebut (focusing on and venting of emotion), menggunakan alkohol atau obat-obatan (alcohol and drug disengagement), mengurangi usaha untuk mengatasi stresor (behavioral disengagement), mengabaikan stresor dengan mengalihkan perhatian dari perilaku atau tujuan yang terhalang oleh stresor (mental disengagement). Mental disengagement merupakan salah satu bentuk behavioral disengagemet dan dilakukan di saat situasi tidak memungkinkan untuk melakukan behavioral disengagement. Walaupun melakukan disengagement terkadang dapat menjadi sangat adaptif, cara-cara seperti ini bersifat disfungsional dan dapat mencegah seseorang untuk mengatasi stres yang dialaminya secara aktif serta menghambat penyesuaian diri (Carver et al., 1989).

Selain menghambat individu untuk mengatasi stres, coping yang negatif atau maladaptif ini juga dapat memprediksi gejala depresi dan regulasi emosi yang buruk dikemudian hari (Heffer \& Willoughby, 2017). Mengingat kehidupan mahasiswa yang tidak dapat terlepas dari berbagai sumber stres, serta berbagai risiko yang dapat terjadi jika stres dibiarkan atau diatasi menggunakan coping yang maladaptif, maka penting untuk melihat jenis coping yang digunakan oleh mahasiswa. Penelitian ini bertujuan untuk mengetahui coping strategies apa yang digunakan oleh mahasiswa. 


\section{Metode}

\section{Partisipan dan Prosedur}

Data dikumpulkan menggunakan online form dengan teknik convenient sampling. Online form dibuat menggunakan platform Google form. Online form tersebut terbagi ke dalam tiga bagian, yakni formulir kesediaan, data demografi, dan kuesioner coping strategies. Bekerjasama dengan Lembaga Survei dan Penelitian (LSP) Unpad, link Google form disebar melalui media sosial yakni, LINE dan Instagram. Responden diminta melengkapi data demografi berupa usia, suku bangsa, agama, asal kota, fakultas, angkatan, tempat tinggal, rutinitas berolahraga, dan keikutsertaan dalam organisasi. Pengumpulan data dilakukan dari tanggal 23 April 2018 sampai dengan 12 September 2018 dan diperoleh 339 responden yang merupakan mahasiswa aktif Universitas Padjadjaran dengan rentang usia 17-23 tahun (M=19.58; $\mathrm{SD}=1.19)$ dari 16 fakultas: Psikologi, Kedokteran, Kedokteran Gigi, Keperawatan, Farmasi, Matematika dan IPA, Perikanan dan Ilmu Kelautan, Peternakan, Pertanian, Teknik Industri Pertanian, Teknik Geologi, Hukum, Ekonomi dan Bisnis, Ilmu Sosial dan Ilmu Politik, Ilmu Komunikasi, dan Ilmu Budaya.

\section{Instrumen}

Alat ukur yang digunakan adalah COPE Inventory (Carver et al., 1989) yang sudah diterjemahkan ke dalam Bahasa Indonesia (Sentani, 2016) yang reabilitasnya $(\alpha=0.872)$ dan validitasnya (CFI>0.9, $\mathrm{t}>1.96)$ telah terbukti. COPE Inventory tersebut terdiri dari 55 butir pernyataan dengan empat pilihan jawaban: tidak pernah (1) hingga selalu (4). Terdapat 15 skala coping strategies, lima di antaranya termasuk ke dalam problem-focused coping (active coping, planning, suppresion of competing activities, restraint coping, dan seeking social support for instrumental reasons); enam lainnya digolongkan ke dalam emotion-focused coping (seeking social support for emotional reasons, positive reinterpretation and growth, denial, acceptance, turning to religion, dan humor); dan empat lainnya dikategorikan sebagai maladaptive coping (focusing on and venting of emotions, behavioral disengagement, mental disengagement, dan alcohol and drug disengagement).

\section{Analisis}

Analisis data dilakukan menggunakan JASP 0.10.2.0 dan Microsoft Office Excel 365. Lima skala yakni, suppresion of competing activities, restraint coping, denial, acceptance, dan behavioral disengagement masing-masing terdiri dari tiga item, sedangkan kesepuluh skala lainnya masing-masing terdiri dari empat item, sehingga transformasi terhadap lima skala tersebut perlu dilakukan terlebih dahulu sebelum analisis lebih lanjut. Transformasi dilakukan agar seluruh skala memiliki rentang skor yang sama dengan skor minimal 4 dan maksimal 16. Normalisasi dan transformasi dilakukan pada kelima skala yang terdiri dari tiga item untuk menyesuaikan dengan skala lainnya yang memiliki empat item dengan rumus $\frac{4 \times n}{3}$ dengan $n=$ skor total dari skala yang akan ditransformasi. Setelah melalui proses transformasi, dilakukan uji normalitas, uji deskriptif, Mann-Whitney, serta uji korelasi. 


\section{Hasil Penelitian}

Distribusi responden berdasarkan demografi dapat dilihat pada Tabel 1. Dari analisis data yang dilakukan (Tabel 2) ditemukan bahwa coping strategies yang paling sering digunakan oleh mahasiswa adalah turning to religion. Korelasi antar coping strategies dapat dilihat pada Tabel 3.

Tabel 1. Demografi Responden

\begin{tabular}{lcc}
\hline & Frekuensi & Persentase \\
\hline Agama & & 79.65 \\
Islam & 270 & 12.09 \\
Kristen katolik & 41 & 6.19 \\
Kristen protestan & 21 & 0.88 \\
Budha & 3 & 0.29 \\
Hindu & 1 & 0.29 \\
Parmalim & 1 & 0.29 \\
Agnostik & 1 & 0.29 \\
Atheis & 1 & \\
\hline Suku bangsa & & 41.59 \\
Sunda & 141 & 30.67 \\
Jawa & 104 & 10.03 \\
Batak & 34 & 6.19 \\
Minang & 21 & 1.18 \\
Tionghoa & 4 & 10.32 \\
Lain-lain & 35 & 84.07 \\
\hline Organisasi & & 15.93 \\
Ya & 285 & \\
Tidak & 54 & 24.78 \\
\hline Olahraga & & 75.22 \\
Ya & 84 & 78.47 \\
\hline Tidak & 255 & 21.53 \\
Sempat tinggal & & \\
Bersama keluarga & 266 & \\
\hline
\end{tabular}

Tabel 2 Deskriptif COPE Inventory

\begin{tabular}{|c|c|c|c|c|c|c|c|}
\hline \multirow[b]{2}{*}{ Coping Strategies } & \multirow[b]{2}{*}{$\begin{array}{l}\text { Skor COPE } \\
\text { Inventory }\end{array}$} & \multicolumn{6}{|c|}{ Skor Berdasarkan Karakteristik } \\
\hline & & $\begin{array}{c}\text { Tinggal } \\
\text { bersama } \\
\text { keluarga }\end{array}$ & $\begin{array}{l}\text { Tinggal } \\
\text { sendiri }\end{array}$ & Berorganisasi & $\begin{array}{c}\text { Tidak } \\
\text { berorganisasi }\end{array}$ & Berolahraga & $\begin{array}{c}\text { Tidak } \\
\text { berolahraga }\end{array}$ \\
\hline Active Coping & $12.04(1.88)$ & $11.85(1.81)$ & $12.09(1.9)$ & $12.02(1.88)$ & $12.09(1.91)$ & $12.48(2.22)^{*}$ & $11.89(1.73)^{*}$ \\
\hline Planning & $12.29(2.22)$ & $12.15(1.88)$ & $12.33(2.31)$ & $12.33(2.16)$ & $12.09(2.52)$ & $12.57(2.55)$ & $12.2(2.10)$ \\
\hline $\begin{array}{l}\text { Suppression of Competing } \\
\text { Activities }\end{array}$ & $11.48(2.22)$ & $11.62(2.23)$ & $11.451(2.23)$ & $11.56(2.23)^{*}$ & $11.06(2.19)^{*}$ & $11.86(2.59)$ & $11.36(2.08)$ \\
\hline Restraint Coping & $11.83(2.2)$ & $11.69(2.27)$ & $11.86(2.18)$ & $11.9(2.23)$ & $11.46(2)$ & $12.08(2.4)$ & $11.74(2.13)$ \\
\hline $\begin{array}{l}\text { Seeking Social Support for } \\
\text { Instrumental Reasons }\end{array}$ & $11.67(2.7)$ & $11.6(2.5)$ & $11.69(2.76)$ & $11.77(2.63)$ & $11.15(3.01)$ & $11.74(2.84)$ & $11.65(2.66)$ \\
\hline $\begin{array}{l}\text { Seeking Social Support for } \\
\text { Emotional Reasons }\end{array}$ & $11.46(2.78)$ & $11.23(2.5)$ & $11.53(2.86)$ & $11.55(2.74)$ & $10.98(2.97)$ & $11.73(2.76)$ & $11.38(2.79)$ \\
\hline $\begin{array}{l}\text { Positive Reinterpretation } \\
\text { and Growth }\end{array}$ & $13.06(1.98)$ & $12.95(1.91)$ & $13.09(2.01)$ & $13.14(1.9)$ & $12.61(2.34)$ & $13.48(2.27)^{* *}$ & $12.92(1.87)^{* *}$ \\
\hline Denial & $9.4(2.97)$ & $9.1(2.86)$ & $9.48(3)$ & $9.47(2.9)$ & $9.037(3.31)$ & $10.4(3.01)^{* * *}$ & $9.07(2.89)^{* * *}$ \\
\hline Acceptance & $12.82(1.93)$ & $12.71(1.81)$ & $12.85(1.97)$ & $12.82(1.95)$ & $12.84(1.87)$ & $13.03(2.15)$ & $12.75(1.85)$ \\
\hline Turning to Religion & $13.67(2.77)$ & $13.59(2.49)$ & $13.69(2.84)$ & $13.69(2.73)$ & $13.54(2.94)$ & $14.19(2.54)^{*}$ & $13.49(2.82)^{*}$ \\
\hline Humor & $7.8(2.05)$ & $7.81(2.02)$ & $7.79(2.06)$ & $7.8(2.06)$ & $7.78(2.03)$ & $7.94(2.25)$ & $7.75(1.98)$ \\
\hline $\begin{array}{l}\text { Focusing on and Venting of } \\
\text { Emotions }\end{array}$ & $11.18(2.43)$ & $11.33(2.24)$ & $11.14(2.48)$ & $11.07(2.41)^{*}$ & $11.76(2.44)^{*}$ & $11.01(2.86)$ & $11.24(2.27)$ \\
\hline Behavioral Disengagement & $7.55(2.78)$ & $8.15(2.85)^{*}$ & $7.38(2.74)^{*}$ & $7.45(2.74)$ & $8.05(2.93)$ & $7.29(3.17)$ & $7.63(2.64)$ \\
\hline Mental Disengagement & $11.15(2.26)$ & $11.05(2.30)$ & $11.18(2.25)$ & $11.2(2.22)$ & $10.93(2.48)$ & $12.36(2.27)^{* * *}$ & $10.76(2.12)^{* * *}$ \\
\hline $\begin{array}{l}\text { Alcohol and Drug } \\
\text { Disengagement }\end{array}$ & $5.45(2.93)$ & $5.95(3.37)$ & $5.31(2.79)$ & $5.34(2.92)$ & $5.98(2.99)$ & $5.87(0.35)$ & $5.31(2.78)$ \\
\hline
\end{tabular}


Catatan: Signifikansi Mann-Whitney ${ }^{*} p \varangle 0.05,{ }^{* *} p \varangle 0.01,{ }^{* * *} p \triangleleft 0.001$

Tabel 3 Korelasi antar COPE Scales

\begin{tabular}{|c|c|c|c|c|c|c|c|c|c|c|c|c|c|c|c|}
\hline & 1. & 2. & 3. & 4. & 5. & 6. & 7. & 8. & 9. & 10. & 11. & 12. & 13. & 14. & 15. \\
\hline 1. & - & & & & & & & & & & & & & & \\
\hline 2. & $0.59^{* * *}$ & - & & & & & & & & & & & & & \\
\hline 3. & $0.55^{* * *}$ & $0.59 * * *$ & - & & & & & & & & & & & & \\
\hline 4. & $0.45^{* * *}$ & $0.51^{* * *}$ & $0.52^{* * *}$ & - & & & & & & & & & & & \\
\hline 5. & $0.38^{* * *}$ & $0.42^{* * *}$ & $0.33^{* * *}$ & $0.29^{* * *}$ & - & & & & & & & & & & \\
\hline 6. & $0.37^{* * *}$ & $0.39 * * *$ & $0.37^{* * *}$ & $0.27^{* * *}$ & $0.81^{* * *}$ & - & & & & & & & & & \\
\hline 7. & $0.49^{* * *}$ & $0.5^{* * *}$ & $0.42^{* * *}$ & $0.4^{* * *}$ & $0.29^{* * *}$ & $0.29^{* * *}$ & - & & & & & & & & \\
\hline 8. & $0.18^{* * *}$ & 0.10 & $0.15^{* *}$ & $0.17^{* *}$ & -0.02 & 0.00 & $0.21^{* * *}$ & - & & & & & & & \\
\hline 10. & $0.31^{* * *}$ & $0.35^{* * *}$ & $0.26^{* * *}$ & $0.25^{* * *}$ & $0.33^{* * *}$ & $0.36^{* * *}$ & $0.39^{* * *}$ & $0.19^{* * *}$ & $0.24^{* * *}$ & - & & & & & \\
\hline 11. & $0.15^{* *}$ & $0.14^{* *}$ & $0.15^{* *}$ & $0.22^{* * *}$ & $0.17^{* *}$ & $0.12^{*}$ & $0.18^{* * *}$ & $0.23^{* * *}$ & $0.17^{* *}$ & 0.04 & - & & & & \\
\hline 12. & $0.2^{* * *}$ & $0.14^{* *}$ & 0.07 & 0.02 & $0.32^{* * *}$ & $0.35^{* * *}$ & -0.08 & $-0.17^{* *}$ & 0.08 & 0.08 & 0.09 & - & & & \\
\hline 13. & $-0.12^{*}$ & $-0.18^{* * *}$ & -0.06 & -0.10 & $-0.11^{*}$ & $-0.17^{* *}$ & $-0.24^{* * *}$ & 0.01 & $-0.16^{* *}$ & $-0.27^{* * *}$ & $0.12^{*}$ & $0.13^{*}$ & - & & \\
\hline 14. & $0.3^{* * *}$ & $0.31^{* * *}$ & $0.25^{* * *}$ & $0.21^{* * *}$ & $0.33^{* * *}$ & $0.33^{* * *}$ & $0.28^{* * *}$ & $0.2^{* * *}$ & $0.12^{*}$ & $0.21^{* * *}$ & $0.23^{* * *}$ & $0.11^{*}$ & -0.03 & - & \\
\hline 15. & -0.04 & -0.01 & -0.02 & -0.10 & 0.01 & -0.07 & $-0.11^{*}$ & $-0.12^{*}$ & -0.05 & $-0.28^{* * *}$ & $0.11^{*}$ & 0.08 & $0.26^{* * *}$ & 0.05 & - \\
\hline
\end{tabular}

Catatan: ${ }^{*} \varangle \triangleleft 0.05,{ }^{* *} p \triangleleft 0.01,{ }^{* * *} p \triangleleft 0.001,1=$ Active Coping, 2=Planning, 3=Suppression of Competing Activities, 4=Restraint Coping, 5=Seeking Social Support for Instrumental Reasons, 6=Seeking Social Support for Emotional Reasons, 7=Positive Reinterpretation and Growth, 8=Denial, 9=Acceptance, 10=Turning to Religion, 11=Humor, 12=Focusing on and Venting of Emotion, 13=Behavioral Disengaement, 14=Mental Disengagement, 15=Alcohol and Drug Disengagement. Rule of thumb: $\varangle 0.3=$ diabaikan, $\varangle .5=$ korelasi rendah, $\varangle 0.7=$ korelasi sedang, $\varangle$.9= korelasi tinggi, $>0.9=$ korelasi sangat tinggi (Mukaka, 2012).

\section{Pembahasan}

Penelitian ini menemukan bahwa turning to religion merupakan coping strategies yang paling sering digunakan oleh mahasiswa. Turning to religion atau religious coping adalah mencari kenyamanan, dukungan, dan arahan dari Tuhan ataupun dari sesuatu yang bersifat spiritual (Carver et al., 1989). Hal ini sejalan dengan penelitian sebelumnya pada subjek di Indonesia bahwa agama merupakan coping yang paling sering digunakan (Fathi, Nasae, \& Thiangchanya, 2012). Hal tersebut dikarenakan masyarakat Indonesia memegang nilai-nilai keagamaan yang tinggi (Aina \& Hermilia Wijayati, 2019). Selain itu, budaya kolektivis di Indonesia pun mungkin berpengaruh dalam hal ini (Henderson, S.; Klöfver, E.; Persson, 2013). Mahasiswa dari Asia lebih sering menggunakan agama sebagai coping strategy dibandingkan mahasiswa dari Eropa (Chai, Krägeloh, Shepherd, \& Billington, 2012).

Religious coping dapat dipilih sebagai coping strategies karena beberapa hal, yang pertama adalah fungsi agama itu sendiri yang dapat menenangkan stres. Mereka yang menggunakan agama sebagai coping memiliki tingkat distress (Gaston-Johansson, Haisfield-Wolfe, Reddick, Goldstein, \& Lawal, 2013) dan gejala depresi yang lebih rendah (Woods, Antoni, Ironson, \& Kling, 1999). Selain itu, agama juga berkaitan dengan coping strategies lainnya (Tabel 2), salah satunya adalah seeking for social support. Terlibat dalam kegiatan kegamaan (Prado et al., 2004), spiritualitas, dan coping berlandaskan spiritualitas (Simoni, Martoneb, \& Kerwinb, 2002) dapat membantu menangani stres dengan cara memberikan social support. Orang-orang mencari social support melalui agama baik untuk alasan emosional maupun instrumental (Carver et al., 1989). Kaitan agama dengan social support ini pun didukung dengan korelasi yang signifikan antara turning to religion dengan seeking social support for instrumental reasons dan seeking social support for emotional reasons. Selain social support, agama juga berkaitan dengan active coping. Hal ini dikarenakan agama dapat dijadikan sebagai cara dalam melakukan active coping (Carver et al., 1989). Selain itu, active coping dapat menjadi perantara antara hubungan religious coping dan rendahnya gejala depresi (Woods, el. al., 1999). Hasil penelitian ini pun menunjukkan adanya korelasi yang signifikan antara active coping dengan turning to religion. Turning to religion juga berkolerasi positif dengan positive reinterpretation and growth, yang mana merupakan coping strategies yang paling sering digunakan berikutnya. 
Positive reinterpretation and growth merupakan usaha untuk memaknakan stresor sebagai hal yang positif. Strategi ini berfungsi sebagai emotion-focused coping (Lazarus, Richard S; Folkman, 1984) untuk mengurangi distres, dan juga memungkinkan individu untuk kembali fokus mengatasi stresor secara langsung dan aktif (Carver et al., 1989). Kaitan positive reinterpretation and growth dengan turning to religion dapat dijelaskan melalui beberapa hal. Pertama, agama merupakan alat bagi individu untuk melakukan positive reinterpretation and growth (Carver et al., 1989). Kedua, agama juga mengajarkan untuk melihat sisi positif dari suatu perkara.

Strategi yang paling sering digunakan berikutnya adalah acceptance. Acceptance juga berkorelasi positif dengan turning to religion. Orang-orang yang beralih pada agama di saat stres kemungkinan juga menerima permasalahan yang dihadapinya. Hal ini masuk akal karena agama juga mengajarkan untuk berserah diri saat sedang menghadapi permasalahan. Berserah diri, atau surrender to God, merupakan strategi coping dimana saat menghadapi permasalahan, individu secara aktif memilih untuk melepaskan keinginannya kepada ketetapan Tuhan (Wong-Mcdonald \& Gorsuch, 2000). Namun, berserah diri bukan berarti pasrah dan tidak mengatasi stresor secara aktif. Sebagaimana yang telah dijelaskan, agama justru berkaitan dengan active coping. Selain itu, dimensi lain yang berkaitan erat dengan active coping, yakni planning, juga berkorelasi signifikan dengan turning to religion, dan merupakan coping strategy yang paling sering digunakan berikutnya, sebelum active coping itu sendiri.

Sementara itu, coping strategy yang paling jarang digunakan oleh mahasiswa adalah penggunaan alcohol and mental disengagement, yang tergolong ke dalam maladaptive coping. Maladaptive coping lainnya, yakni behavior disengagement juga tidak begitu sering digunakan. Sementara bentuk maladaptive coping mental disengagement dan focusing on and venting of emotion cukup sering digunakan oleh mahasiswa. Mengingat bahwa strategi yang paling sering digunakan adalah turning to religion, tidak mengherankan jika penggunaan alkohol dan obat-obatan menjadi strategi yang paling jarang digunakan. Penggunaan alkohol dan obat-obatan dilarang atau tidak dianjurkan oleh beberapa agama, khususnya agama yang sebagian besar dianut oleh responden yakni Islam. Hal ini sejalan dengan studi sebelumnya yang menemukan bahwa penggunaan religious coping berkorelasi dengan tingkat konsumsi alkohol yang rendah (Krause, Pargament, Hill, \& Ironson, 2018). Sementara studi lainnya (Carver et al., 1989) hanya menemukan korelasi negatif antara kedua coping strategies tersebut ketika mengukur coping strategies situasional, bukan disposisional. Artinya, dalam penelitian-penelitian tersebut, turning to religion tidak berkaitan dengan konsumsi alkohol dan obat-obatan sebagai strategi coping secara umum. Kedua strategi ini saling berhubungan negatif hanya jika digunakan dalam situasi stres yang sama. Penelitian ini hanya mengukur coping strategies disposisional, atau kecenderungan seseorang untuk menggunakan strategi tertentu dalam menghadapi stres secara umum. Penemuan korelasi negatif antara kedua strategi tersebut dalam penelitian ini mungkin disebabkan oleh faktor agama yang kuat di Indonesia.

Perbedaan yang signifikan $\left(p=0.008, r_{r b}=0.169\right)$, pada penggunaan strategi turning to religion ditemukan antara mahasiswa yang rutin berolahraga dengan yang tidak. Perbedaan yang signifikan juga ditemukan pada penggunaan strategi active coping $\left(p=0.011, r_{r b}=0.164\right)$. Mahasiswa yang rutin berolahraga lebih sering menggunakan active coping dibandingkan mereka yang tidak. Perbedaan yang signifikan juga ditemukan pada penggunaan strategi positive reinterpretation and growth $\left(p=0.004, r_{r b}=\right.$ 0.188). Mahasiswa yang rutin berolahraga lebih sering menggunakan positive reinterpretation and growth sebagai coping strategy dibandingkan mereka yang tidak. Perbedaan yang signifikan juga ditemukan pada penggunaan strategi denial $\left(p<0.001, r_{r b}=0.278\right.$ ). Mahasiswa yang rutin berolahraga lebih sering menggunakan strategi denial dibandingkan mereka yang tidak. Perbedaan yang signifikan juga ditemukan pada penggunaan strategi mental disengagement $\left(p<0.001, r_{r b}=0.406\right)$. Mahasiswa yang rutin berolahraga lebih sering menggunakan mental disengagement dibandingkan mereka yang tidak. Penelitian sebelumnya mengimplikasikan bahwa olahraga berkaitan dengan problem-focused coping dan 
pemilihan coping strategies yang tepat untuk mengurangi stres, sekaligus menurunkan intensitas stres (Azizi, 2011). Akan tetapi, data dalam penelitian ini menunjukkan bahwa kaitan olahraga dengan coping strategies cukup bervariasi. Olahraga tidak hanya berkaitan dengan coping strategies yang tergolong ke dalam problem-focused coping (active coping), tetapi juga emotion-focused coping (turning to religion, positive reinterpretation and growth, dan denial) dan maladaptive coping (mental disengagement), sehingga tidak dapat disimpulkan memiliki dampak yang baik terhadap coping strategies yang adaptif ataupun problemfocused. Penelitian lainnya mengimplikasikan bahwa olahraga bisa jadi merupakan salah satu bentuk dari disengagement coping, yang dapat memunculkan perilaku berolahraga yang didorong dengan alasan yang keliru (Loumidis \& Wells, 2001). Tampaknya, kaitan olahraga dengan jenis coping strategies bergantung pada alasan berolahraga. Perilaku berolahraga tetap dapat memunculkan berbagai manfaat seperti menurunkan stres. Akan tetapi, motivasi di balik perilaku tersebut dapat menunjukan berbagai implikasi yang mungkin berkaitan dengan maladaptive belief yang berkaitan dengan clinical disorder, seperti keyakinan bahwa kurangnya olahraga dapat memperburuk penampilan yang berkaitan dengan eating disorder (Loumidis \& Wells, 2001). Olahraga mungkin dapat direkomendasikan sebagai salah satu bentuk coping strategies yang adaptif dan bermanfaat, tetapi hal ini perlu diiringi dengan melihat motivasi yang mendorong perilaku berolahraga untuk melihat apakah terdapat permasalahan yang lebih mendalam selain stres yang dihadapi.

Beberapa perbedaan juga ditemukan antara mahasiswa yang berorganisasi dan tidak berorganisasi. Perbedaan ini meliputi penggunaan strategi suppression of competing activities $\left(p=0.017, r_{r b}=0.178\right)$, focusing on and venting of emotions $\left(p=0.015, r_{r b}=-0.186\right)$, dan alcohol and drug disengagement $\left(p=0.031, r_{r b}=\right.$ 0.122). Mahasiswa yang berorganisasi lebih sering menggunakan strategi suppression of competing activities dibandingkan mereka yang tidak berorganisasi. Hal ini mungkin dikarenakan kegiatan berorganisasi menuntut individu untuk dapat mengabaikan aktivitas yang tidak relevan saat harus berfokus pada suatu tujuan atau aktivitas tertentu. Sementara pada penggunaan strategi focusing on and venting of emotions, mahasiswa yang tidak berorganisasi lebih sering menggunakannya dibandingkan mereka yang berorganisasi. Hal ini mungkin dikarenakan mereka yang aktif dalam kegiatan berorganisasi lebih pandai dalam mengenali emosinya dan menggunakannya untuk mengatasi konflik dan permasalahan (Eckert, 2014). Begitu pula dengan penggunaan strategi alcohol and drug disengagement, mahasiswa yang tidak berorganisasi lebih sering menggunakan strategi tersebut dibandingkan mereka yang berogranisasi. Hal ini sesuai dengan penelitian sebelumnya yang menunjukkan bahwa kegiatan ekstrakurikuler berkaitan dengan rendahnya konsumsi alkohol dan obatobatan (Cooley, 1992). Dari data yang telah dipaparkan tersebut, tampaknya organisasi berkaitan dengan penggunaan coping strategies yang adaptif.

Perbedaan juga ditemukan antara mahasiswa yang tinggal sendiri dan mereka yang tinggal dengan keluarga. Akan tetapi perbedaan ini hanya ditemukan pada satu coping strategy, yakni behavioral disengagement $\left(p=0.20, r_{r b}=0.154\right)$. Mahasiswa yang tinggal dengan keluarganya lebih sering menggunakan strategi behavioural disengagement dibandingkan mahasiswa yang tinggal sendiri, seperti kos ataupun mengontrak. Dari data tersebut, tinggal terpisah dari keluarga tampaknya lebih baik dalam menjaga mahasiswa dari menggunakan coping strategy yang maladaptif khusunya behavioral disengagement. Hal ini sesuai dengan penemuan sebelumnya (Fares et al., 2016) yang menduga bahwa mereka yang tinggal tinggal dengan keluarga akan menghabiskan lebih banyak waktu dengan keluarganya yang akhirnya memakan jatah waktu yang dapat digunakan untuk melakukan hal yang seharusnya mereka lakukan.

Signifikansi perbedaan-perbedaan yang disebutkan di atas hanya menyatakan bahwa perbedaanperbedaan yang ditemukan dalam penelitian ini kemungkinan bukanlah suatu kebetulan, tetapi tidak menyatakan tentang seberapa besar perbedaan tersebut (Sullivan \& Feinn, 2012). Sebagian besar 
perbedaan yang ditemukan dalam penelitian ini memiliki effect size yang kecil $\left(0.1 \leq\left|r_{r b}\right|<0.3\right.$; Maher, Markey, \& Ebert-May, 2013; Rosenthal, 1996; Tomczak \& Tomczak, 2014). Hanya perbedaan penggunaan mental disengagement di antara mahasiswa yang berolahraga dan yang tidak, yang memiliki effect size medium $\left(0.3 \leq\left|r_{r b}\right|<0.5\right)$ Meskipun perbedaan-perbedaan tersebut signifikan secara statistik, karena effect size-nya kecil, secara praktikal perbedaan-perbedaan tersebut tidak terlalu signifikan (Maher et al., 2013).

\section{Kesimpulan dan Saran}

Coping strategies yang paling sering digunakan oleh mahasiswa Universitas Padjadjaran adalah coping strateges yang adaptif yaitu, turning to religion, yang kemudian diikuti oleh positive reinterpretation and growth dan acceptance. Akan tetapi, maladaptive coping, seperti focusing on and venting of emotion dan mental disengagement juga masih cukup sering digunakan. Intervensi dapat dirancang untuk mengoptimalkan coping strategies yang sudah sering digunakan serta mengurangi kedua maladaptive coping yang sering digunakan.

Penemuan bahwa mahasiswa yang rutin berolahraga lebih sering menggunakan mental disengagement perlu diteliti lebih lanjut untuk mencari tahu alasan dan implikasinya. Penelitian selanjutnya juga perlu mempertimbangkan tingkat stres yang dialami oleh individu dan melihat lebih lanjut keefektivan coping strategies secara disposisional maupun situasional.

\section{Daftar Pustaka}

Aina, Q., \& Hermilia Wijayati, P. (2019). Coping the Academic Stress: The Way the Students Dealing with Stress. International Seminar on Language, Education, and Culture, 3(10), 212-223. https://doi.org/10.18502/kss.v3i10.3903

Azizi, M. (2011). Effects of doing physical exercises on stress-coping strategies and the intensity of the stress experienced by university students in Zabol, Southeastern Iran. Procedia - Social and Behavioral Sciences, 30, 372-375. https://doi.org/10.1016/.sbspro.2011.10.073

Carver, C. S., Scheier, M. F., \& Weintraub, K. J. (1989). Assessing Coping Strategies: A Theoretically Based Approach. Journal of Personality and Social Psychology, 56(2), 267-283. https://doi.org/10.1037/0022-3514.56.2.267

Chai, P. P. M., Krägeloh, C. U., Shepherd, D., \& Billington, R. (2012). Stress and quality of life in international and domestic university students: Cultural differences in the use of religious coping. Mental Health, Religion and Culture, 15(3), 265-277. https://doi.org/10.1080/13674676.2011.571665

Cohen, S., Janicki-Deverts, D., \& Miller, G. E. (2007). Psychological Stress and Disease. Journal of the American Medical Association, 298(14), 1685-1687.

Cooley, V. E. (1992). A Study To Determine the Effect of Extracurricular Participation on Student Alcohol and Drug Use in Secondary Schools. Chicago. 
Eckert, D. (2014). Emotional intelligence assessment of Undergraduate students involved in student organization at a research institution in northern California. California State University.

Fares, J., Saadeddin, Z., Al Tabosh, H., Aridi, H., El Mouhayyar, C., Koleilat, M. K., ... El Asmar, K. (2016). Extracurricular activities associated with stress and burnout in preclinical medical students. Journal of Epidemiology and Global Health, 6(3), 177-185. https://doi.org/10.1016/.jegh.2015.10.003

Fathi, A., Nasae, T., \& Thiangchanya, P. (2012). Workplace Stressors and Coping Strategies Among Public Hospital Nurses in Medan, Indonesia. Nurse Media Journal of Nursing, 2(1), 315-324.

Folkman, S., \& Lazarus, R. S. (1985). If it changes it must be a process. Journal of Personality and Social Psychology, 48(1), 150-170. Retrieved from http:/psycnet.apa.org/fulltext/1985-18642-001.pdf

Gaston-Johansson, F., Haisfield-Wolfe, M. E., Reddick, B., Goldstein, N., \& Lawal, T. A. (2013). The Relationships Among Coping Strategies, Religious Coping, and Spirituality in African American Women With Breast Cancer Receiving Chemotherapy. Oncology Nursing Forum, 40(2), 120-131. https://doi.org/10.1188/13.onf.120-131

Heffer, T., \& Willoughby, T. (2017). A count of coping strategies: A longitudinal study investigating an alternative method to understanding coping and adjustment. PLOS ONE, 12(10), e0186057. https://doi.org/10.1371 gournal.pone.0186057

Henderson, S.; Klöfver, E.; Persson, A. (2013). Differences in Health, Stress and Coping - a Cross Cultural Comparison (UNIVERSITY OF BORÅS). https://doi.org/10.1080/10903120701707955

Krause, N., Pargament, K. I., Hill, P. C., \& Ironson, G. (2018). Assessing gender differences in the relationship between religious coping responses and alcohol consumption. Mental Health, Religion and Culture, 21(1), 93-104. https://doi.org/10.1080/13674676.2018.1455652

Lazarus, Richard S; Folkman, S. (1984). Stress, appraisal, and coping. In Behaviour Research and Therapy (Vol. 91). https://doi.org/10.1016/0005-7967(85)90087-7

Lazarus, R. S. (1993). From Psychological Stress to the Emotions: A History of Changing Outlooks. Annual Review of Psychology, 44(1), 1-21. https://doi.org/10.1146/annurev.psych.44.1.1

Li, C.-T., Cao, J., \& Li, T. M. H. (2016). Eustress or distress. Proceedings of the 2016 ACM International Joint Conference on Pervasive and Ubiquitous Computing Adjunct - UbiComp '16, 1209-1217. https://doi.org/10.1145/2968219.2968309

Loumidis, K., \& Wells, A. (2001). Exercising for the Wrong Reasons: Relationships among Eating Disorder Beliefs, Dysfunctional Exercise Beliefs and Coping. Clinical Psychology and Psychotherapy, 8(6), 416-423. https://doi.org/10.1002/cpp.298

Maher, J. M., Markey, J. C., \& Ebert-May, D. (2013). The other half of the story: Effect size analysis in quantitative research. CBE Life Sciences Education, 12(3), 345-351. https://doi.org/10.1187/cbe.13-040082

Melaku, L., Mossie, A., \& Negash, A. (2015). Stress among Medical Students and Its Association with Substance Use and Academic Performance. Journal of Biomedical Education, 2015, 1-9. https://doi.org/10.1155/2015/149509

Mukaka, M. M. (2012). Statistics Corner: A guide to appropriate use of Correlation coefficient in medical research. Malawi Medical Journal, 24(3), 69-71. https://doi.org/10.1016/.cmpb.2016.01.020

Prado, G., Feaster, D. J., Schwartz, S. J., Pratt, I. A., Smith, L., \& Szapocznik, J. (2004). Religious 
involvement, coping, social support, and psychological distress in HIV-seropositive African American Mothers. AIDS and Behavior, 8(3), 221-235. https://doi.org/10.1023/B:AIBE.0000044071.27130.46

Pritchard, M. E., Wilson, G. S., \& Yamnitz, B. (2007). What predicts adjustment among college students? A longitudinal panel study. Journal of American College Health, 56(1), 15-21. https://doi.org/10.3200/ACH.56.1.15-22

Rosenthal, J. A. (1996). Qualitative Descriptors of Strength of Association and Effect Size. Journal of Social Service Research, 21(4), 37-59. https://doi.org/10.1300/1079v21n04 02

Sajid, A., Ahmad, T., \& Khalid, T. (2015). Stress in medical undergraduates; its association with academic performance. Bangladesh Journal of Medical Science, 14(2), 135-141. https://doi.org/10.1089/ten.tea.2015.0461

Schwabe, L., Joëls, M., Roozendaal, B., Wolf, O. T., \& Oitzl, M. S. (2012). Stress effects on memory: An update and integration. Neuroscience and Biobehavioral Reviews, 36(7), 1740-1749. https://doi.org/10.1016/.neubiorev.2011.07.002

Sentani, S. R. E. (2016). Gambaran Bentuk Coping Stress Mahasiswa Fakultas Pikologi Universitas Padjadjaran yang Mengalami Stress Akademik. Universitas Padjadjaran.

Shansky, R. M., \& Lipps, J. (2013). Stress-induced cognitive dysfunction: hormone-neurotransmitter interactions in the prefrontal cortex. Frontiers in human neuroscience, 7, 123.

Simoni, J. M., Martoneb, M. G., \& Kerwinb, J. F. (2002). Spirituality and psychological adaptation among women with HIV/AIDS: Implications for counseling. Journal of Counseling Psychology, 49(2), 139-147. https://doi.org/10.1037/0022-0167.49.2.139

Sullivan, G. M., \& Feinn, R. (2012). Using Effect Size-or Why the p-Value Is Not Enough. Journal of Graduate Medical Education, 4(3), 279-282. https://doi.org/10.4300/gme-d-12-00156.1

Tomczak, M., \& Tomczak, E. (2014). The need to report effect size estimates revisited. An overview of some recommended measures of effect size. Trends in Sport Sciences, 1(21), 19-25. Retrieved from http://www.wbc.poznan.pl/Content/325867/5 Trends_Vol21_2014_no1_20.pdf

Wong-Mcdonald, A., \& Gorsuch, R. L. (2000). Surrender to God: An Additional Coping Style? Journal of Psychology and Theology, 28(2), 149-161. https://doi.org/10.1177 009164710002800207

Woods, T. E., Antoni, M. H., Ironson, G. H., \& Kling, D. W. (1999). Religiosity is associated with affective and immune status in symptomatic HIV-infected gay men. Journal of Psychosomatic Research, 46(2), 165-176. https://doi.org/10.1016/50022-3999(98)00078-6 
